\title{
Is there a latitudinal gradient in seed production?
}

\author{
Angela T. Moles, lan J. Wright, Andrew J. Pitman, Brad R. Murray and Mark Westoby \\ A.T.Moles (a.moles@unsw.edu.au),Evolution \& Ecology Research Centre, School of Biological, Earth and Environmental Sciences, Univ. of \\ New South Wales, NSW 2052, Australia. - I. J. Wright and M. Westoby, Dept of Biological Sciences, Macquarie Univ., NSW 2109, Australia. \\ - A. J. Pitman, Climate Change Research Centre, Univ. of New South Wales, NSW 2052, Australia. - B. R. Murray, Inst. for Water and \\ Environmental Resource Management, Univ. of Technology, Sydney, NSW 2065, Australia.
}

\begin{abstract}
We compiled data from seed rain studies at 33 sites from around the world to determine whether the greater mean seed mass of tropical plants is associated with production of fewer seeds per square meter of ground. We found no significant linear relationship between latitude and annual seed rain density, but found some evidence for a mid-latitude peak in seed rain density (quadratic relationship, $\mathrm{p}=0.018 ; \mathrm{R}^{2}=0.23$ ). Combining seed rain data with seed mass data suggests that vegetation at the equator produces between 19 and 128 times more total mass of seed per year than does vegetation at $60^{\circ}$. This gradient in seed production would far outweigh the doubling in net primary productivity (NPP) over the same range of latitudes. Thus, our (admittedly small) dataset suggests that tropical vegetation allocates a much greater proportion of NPP to reproduction. This raises two important questions for the future: 1) why might tropical vegetation commit more energy to seed production than vegetation further from the equator? 2) What aspect of plant growth might receive proportionally less energy in tropical ecosystems?
\end{abstract}

On average, plant species in tropical ecosystems produce larger seeds than do species in temperate ecosystems (Levin 1974, Lord et al. 1997, Moles and Westoby 2003). In fact, there is a 320 -fold increase in mean seed mass between $60^{\circ}$ and the equator (Moles et al. 2007). The relationship between seed mass and latitude is best described as a step function, with mean seed mass decreasing by $0.026 \log _{10}$ units per degree within 23 degrees of the equator, dropping by $0.86 \log _{10}$ units at $23^{\circ}$, then declining at $0.017 \log _{10}$ units per degree out to $60^{\circ}$ (Moles et al. 2007).

Among coexisting species, the number of seeds produced per year per unit canopy area (or plant mass) decreases isometrically with seed mass (Aarssen and Jordan 2001, Henery and Westoby 2001). If this finding extended across latitudinal gradients, then the larger seed mass of tropical species would be associated with a concomitant decrease in the number of seeds produced (that is, we would expect vegetation at $60^{\circ}$ to produce 320 times more seeds per square metre of ground than does vegetation at the equator). We tested this prediction by combining data on seed rain and seed mass from the literature.

\section{Is there a latitudinal gradient in seed rain density?}

We searched the Biosis/ISI Web of Science databases for papers containing the term "seed rain", "seed production" or "seed fall" published in English between 1969 and 9 February, 2008. We aimed to include only studies that quantified natural seed production for entire communities. We therefore excluded studies undertaken in sites that are not representative of the natural vegetation of an area (such as mines, pastures in recently cleared tropical rainforests, plantations and cropping systems). We excluded sites undergoing rapid changes in species composition (e.g. areas experiencing biological invasion, and sites recently affected by landslides, hurricanes or volcanism). Studies in which seed rain was estimated through germination were also excluded, as these estimates are reduced by losses to postdispersal seed predators. Where data were available for the same site from different years, we calculated average annual seed production. Unpublished data from rainforest near Cairns, Australia (gathered by W. Edwards) were also included. Our search yielded total seed rain data from 34 studies from 33 sites (Supplementary material, Appendix 1). Different studies used different seed trap designs, and the style of trap could conceivably affect the data (Kollmann and Goetze 1998). However, there were not enough data available to control for seed trap type in our analyses. Ideally, we would have used pre-dispersal seed production data (to ensure that all of the seeds produced in an area were counted). However, these data were simply not available for whole communities. Data for seed rain density, seed mass and NPP were strongly right-skewed. They were therefore $\log _{10}$-transformed before analysis. 
We began by looking for a linear relationship between seed rain and latitude, since this was the logical first-order alternative to a null-hypothesis of no relationship. A linear model did not explain a significant proportion of the variation in seed rain density $\left(\mathrm{p}=0.86 ; \mathrm{R}^{2}=0.001 ; \mathrm{n}=33\right.$; Fig. 1A).

Could combining results from different ecosystems have obscured relationships between seed rain density and latitude? It does not seem so. No relationship was found within forests $(n=18)$, or within grasslands $(n=12)$, the two major vegetation types represented (both $\mathrm{p}>0.2$ ). However, mean seed rain density was higher in grasslands than in forests ( $\mathrm{t}$-test $\mathrm{p}=0.001)$. This is consistent with known shifts in mean seed mass between shaded and open environments, and between woody and herbaceous growth forms (Levin 1974, Salisbury 1974, Foster and Janson 1985).

Next we used a model containing terms for both altitude and latitude to ask whether combining data from sites with different altitudes might have obscured a relationship between latitude and seed rain density. Altitude did not have a significant effect in this model $(\mathrm{p}=0.77)$, and the overall model was not significant $\left(\mathrm{p}=0.57 ; \mathrm{R}^{2}=0.05 ; \mathrm{n}=\right.$ 23). That is, variation in altitude between sites was not
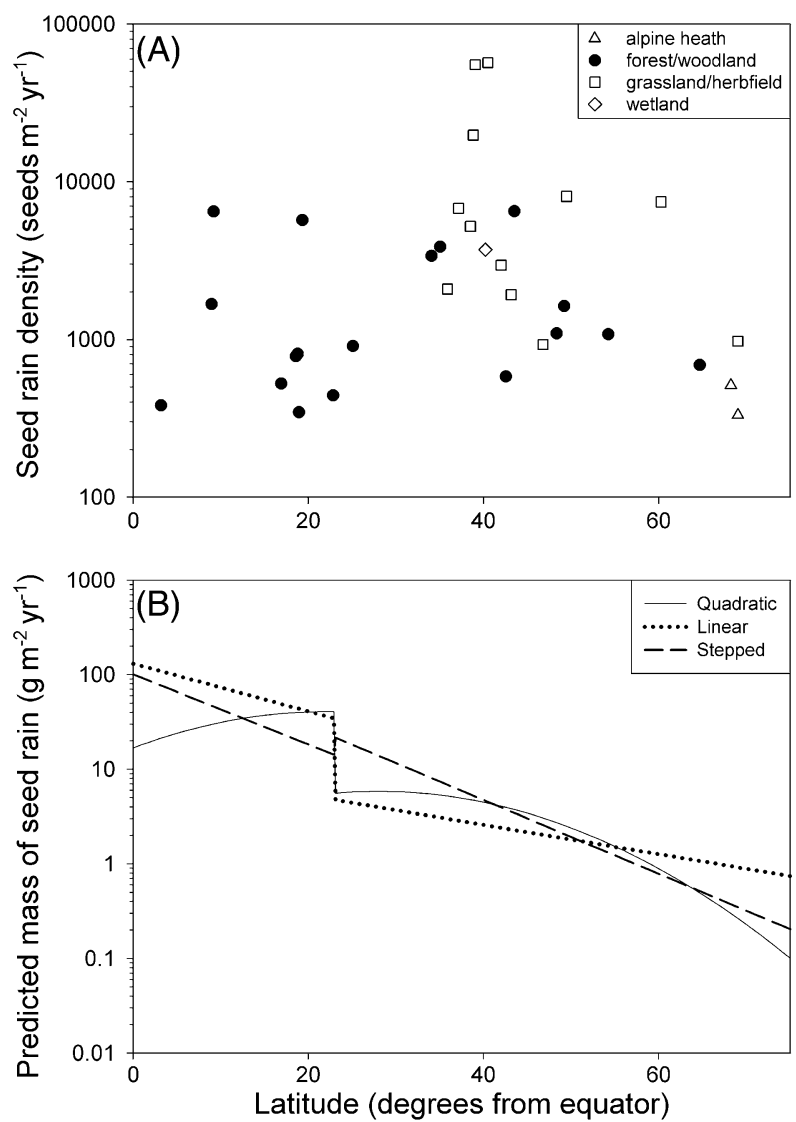

Figure 1. (A) The relationship between latitude and seed rain density. (B) The relationship between latitude and the predicted total mass of seed produced, under each of three models for the latitudinal gradient in seed rain density (linear, stepped and quadratic; see the text for a full description of each model). Each line is the product of seed rain density under one model, and seed mass. The step at the edge of the tropics in these lines results from the step in seed mass at the edge of the tropics (Moles et al. 2007). obscuring a relationship between latitude and seed rain density.

Post-hoc examination of the data suggested a midlatitude peak in seed rain density. We therefore fitted a quadratic relationship to the data. This provided a reasonably good fit $\left(\mathrm{p}=0.018 ; \mathrm{R}^{2}=0.23 ; \mathrm{n}=33\right)$. We also asked whether a stepped relationship might fit the data, since this is what one would predict if seed rain density were an inverse function of the stepped relationship between seed mass and latitude (Moles et al. 2007). With the step located at $23^{\circ}$, this model explained $26 \%$ of the variation in seed rain density $(p=0.03)$. Although statistically significant, these functions provide only a coarse description of the variation in seed rain density. Regardless of the form of the line fitted to these data, it was clearly different to what we would expect if the trade-off between seed mass and seed number seen within sites extended across sites along the latitudinal gradient.

\section{Is there a latitudinal gradient in the total mass of seed falling in the seed rain?}

Our hypothesis was that the negative relationship between seed mass and latitude would be balanced by a positive relationship between seed rain density and latitude. If seeds are larger in the tropics, and there are similar densities of seeds falling in the seed rain, then one might expect the total mass of seed rain to be greater in the tropics than it is closer to the poles.

Unfortunately, we were not able to gather data on mean seed mass, or on the total mass of seed rain for sufficient sites to perform a straight-forward analysis of latitude vs total mass of seed rain. We therefore estimated total mass of seed produced by multiplying the predicted seed rain density under each of the three models described above (linear, stepped and quadratic) by the mean mass of seeds produced at corresponding latitudes (from Moles et al.'s 2007 analysis of seed mass vs latitude for 11481 species $\times$ site combinations from around the world). This approach is based on the log-normal distribution of seed masses at a given site (Leishman et al. 2000), combined with the inverse relationship between seed size and the number of seeds produced per square metre of ground occupied (Aarssen and Jordan 2001, Henery and Westoby 2001, see Supplementary material, Appendix 2 for details).

All three models (linear, quadratic and stepped) predicted a greater total mass of seed fall in the tropics than in temperate regions (Fig. 1B). The total mass of seed produced at the equator was estimated to be 19 times greater than at $60^{\circ}$ under a quadratic relationship between seed rain density and latitude, 103 times greater under the stepped model, and 128 times greater under a linear model. Thus, our conclusion is qualitatively unaffected by our choice of model. Vegetation in the tropics appeared to produce a far greater mass of seed per unit area than does vegetation in temperate regions.

One potential source of bias in this dataset was the possible under-sampling of very small-seeded species in tropical environments (perhaps because tropical researchers used larger mesh in their seed traps on account of the generally larger seeds). However, omitting data for all the 
small-seeded species is more likely to lead to an underestimate of total mass of the seed rain in the tropics than an overestimate (Supplementary material, Appendix 2).

Clearly, these analyses were only a first look at latitudinal gradients in seed production. However, if the total mass of seeds produced per year was higher in plant communities closer to the equator, this would raise some really interesting questions, such as:

\section{1) Why might tropical vegetation commit more energy to seed production?}

It seemed possible that a latitudinal gradient in herbivory (Coley and Aide 1991, Coley and Barone 1996, Swihart and Bryant 2001), seed predation, pathogen attack, or competition for regeneration niches might generate a latitudinal gradient in the seed mass required to attain a given level of seedling survival. Another possibility was that larger seeds might be necessary to counterbalance the greater metabolic costs associated with seedling establishment at relatively high temperatures in the tropics (Lord et al. 1997, Murray et al. 2004), or to fund higher allocation to seedling defence (which might be necessary to counter greater activity of herbivores or pathogens in tropical ecosystems). However, previous studies have found no relationship between latitude and seedling survival, or the seed mass required to attain a given level of seedling survival (Moles et al. 2004), or between latitude and the proportion of seeds lost to post-dispersal seed predation (Moles and Westoby 2003). One further possibility is that the greater seed production in tropical systems might be related to the difficulty of maintaining a seed bank under tropical conditions.

\section{2) Could a latitudinal gradient in net primary productivity account for the gradient in seed production?}

We began by investigating the relationship between seed rain density and net primary productivity. Actual field measurements of NPP were not available for most of our seed rain sites. We therefore estimated NPP for each location using BIOME4 (Kaplan et al. 2003), a coupled biogeography and biogeochemistry model. BIOME4 uses climate and soil information linked to an ecophysiologically-based photosynthesis and stomatal behaviour model, to simulate NPP for a range of plant functional types. The relationship between seed rain density and NPP appears to be triangular: sites with low NPP tended to have low seed rain density, while sites with higher NPP may have had either high or low seed rain density. However, the linear relationship between seed rain density and NPP was not statistically significant $\left(\mathrm{p}=0.08, \mathrm{R}^{2}=0.11 ; \mathrm{n}=27\right.$; Fig. 2$)$.

Next, we asked whether the latitudinal gradient in NPP was steep enough to explain the latitudinal gradient in the total mass of seed produced. Since we were asking about the general trend in NPP rather than NPP for particular sites, we used Olson et al.'s (2001) compilation of field-measured

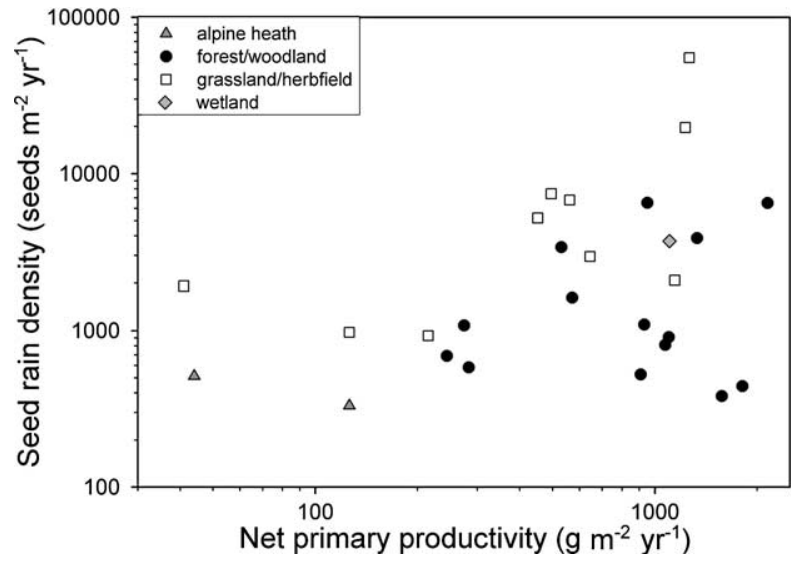

Figure 2. The relationship between seed rain density and net primary productivity.

NPP data. These data showed a very gradual decline in NPP from the equator to $55^{\circ}$ latitude, then a steep decline from $55^{\circ}$ towards the poles (Fig. 3). While there was about 9-fold variation in NPP among sites located between the equator and $10^{\circ}$ and 9-fold variation among sites located between $55^{\circ}$ and $65^{\circ}$, (geometric) mean NPP dropped from $656 \mathrm{~g} \mathrm{~m}^{-2} \mathrm{yr}^{-1}$ to $306 \mathrm{~g} \mathrm{~m}^{-2} \mathrm{yr}^{-1}$ between these geographic regions. Thus, across $60^{\circ}$ latitude, mean NPP approximately doubled, while the total mass of seed falling in the seed rain increased by 19 to 128 -fold. It is therefore unlikely that shifts in NPP are sufficient to account for shifts in the total mass of seed produced (with the possible exception of sites $>50^{\circ}$ from the equator).

There is clearly a great deal of variation in both the density of seed rain and the total mass of seeds produced at a given latitude. In the previous analyses, we multiplied the mean estimated seed rain density for a latitude by the mean seed mass at that latitude, without considering this variation. We therefore asked "what is the shallowest slope of the latitudinal gradient in the total mass of seed production that would be consistent with our data?" To answer this question, we recalculated the total mass of seed rain falling using the $95 \%$ confidence interval upper boundary for the slope of the relationship between seed rain density and latitude (slope $=0.013$ ), multiplied by the $95 \%$ confidence interval upper boundary for the slope of the relationship between latitude and seed mass (tropical slope $=-0.016$; temperate slope $=-0.014$ ). That is, we multiplied the least steep relationship between latitude and seed rain density by the least steep relationship between seed mass and latitude. Even under this extreme scenario, the estimated total mass produced by vegetation at the tropics was still 14 times greater than the total mass of seed produced by vegetation at $60^{\circ}$. Thus, our data (limited though they are) are simply not consistent with the idea that the latitudinal gradient in the total mass of seed rain could be explained by the latitudinal gradient in net primary productivity. Vegetation in tropical ecosystems appears to allocate a greater proportion of NPP to seed production than does vegetation further from the equator. 


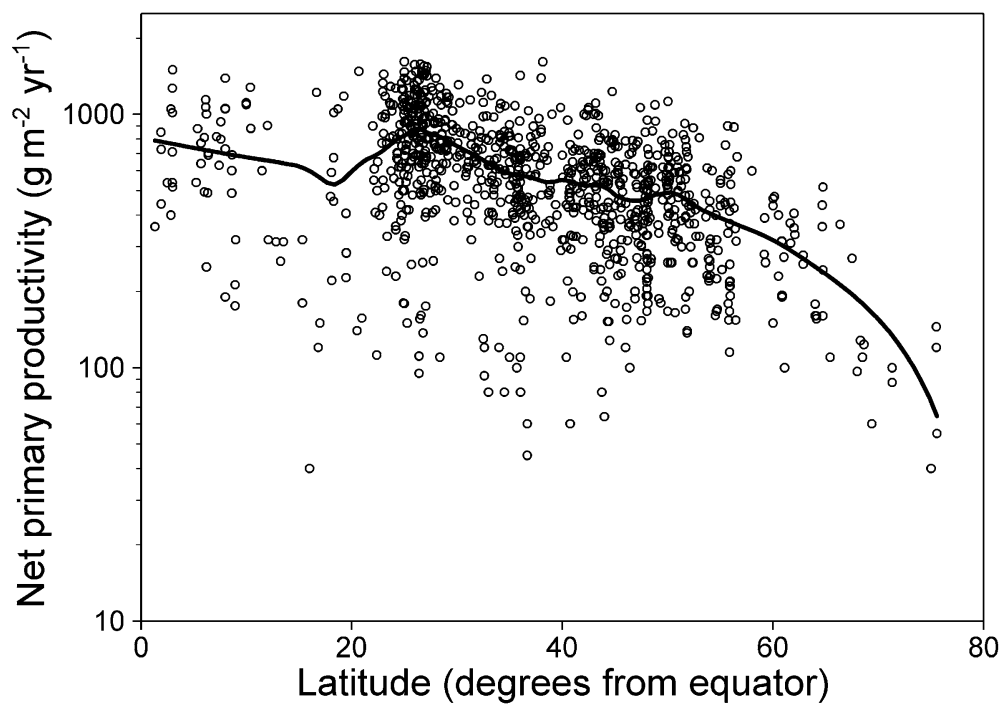

Figure 3. The relationship between latitude and net primary productivity. Data from Olsen et al. (2001), excluding data from pastures, crop lands and plantations. The line shows a loess curve, fit using Sigmaplot 8.0. We selected the loess curve as it allows for a complex non-linear relationship between latitude and NPP (as might be expected if latitude were a product of several factors such as incoming radiation, water availability and soil fertility).

\section{What aspects of plant growth might receive proportionally less energy in the tropics?}

Plants generally allocate $2-50 \%$ of their NPP to reproduction (Harper and Ogden 1970, Howarth and Williams 1972, Wilson and Thompson 1989, Bazzaz et al. 2000). Some of this energy is used to produce flowers, nectar and accessory structures such as fruit, while some is incorporated in seeds. Cross-species studies in Australia have indicated approximately isometric scaling of accessory costs to seed mass (Henery and Westoby 2001, Moles et al. 2003). Thus, it seems unlikely that (generally) larger seeded species in the tropics have lower accessory costs - which could have led to the observed greater seed production at a similar NPP. A second possibility is that the greater allocation to sexual reproduction in the tropics might be related to a latitudinal gradient in the proportion of clonal plants. If tropical species are less likely to allocate energy to asexual reproduction, they might have more energy available for seed production. There is insufficient evidence to test this idea at present. A third possibility is that one or more components of vegetative growth are receiving decreased allocation in the tropics. This might be related to the greater abundance of lianas and epiphytes (which make use of other plants' support structures rather than investing energy in building their own) in many tropical ecosystems. However, recent studies have described a set of allocation rules governing partitioning of biomass among leaf, root and stem across a wide range of communities (Enquist and Niklas 2002, Niklas and Enquist 2002, 2003). Both theoretical and empirical derivations conform to the view that increased annual growth is associated with equivalent increases in the production of stem, root, leaf and reproductive tissue, suggesting an increase in site-based seed mass production in proportion to NPP. Furthermore, there was no relationship between latitude and the ratio of above-ground to below-ground NPP (Olson et al. 2001; $\mathrm{p}=0.09 ; \mathrm{n}=160 ; \mathrm{R}^{2}=0.01$ ). Thus, it is not clear which aspects of vegetative growth might receive less energy in the tropics.

\section{Summary}

Compilation of seed rain data from around the world indicates that greater mean seed mass in the tropics is not balanced by the production of a smaller number of seeds. Vegetation in the tropics appears to produce a far greater total mass of seeds than does vegetation at $60^{\circ}$. This gradient in the total mass of seed produced appears to be much steeper than the gradient in NPP. These patterns raise questions regarding global patterns in seed and seedling mortality, and latitudinal gradients in resource allocation in plants.

Acknowledgements - Thanks to Connie Clark for seed fall data from Cameroon, Will Edwards for seed fall data from Cairns, Australia, Jed Kaplan for providing BIOME4, to Paul Chachelle for updating the literature review in 2008, and to Hans Henrik Bruun (who suggested that the latitudinal gradient in seed mass production might be related to a latitudinal gradient in clonality), K. C. Burns (who suggested that the high proportion of epiphytes and lianas in tropical forests might contribute to their higher total seed production), Michelle Leishman, Guy Midgely, Joe Wright and two anonymous reviewers for comments on the manuscript.

\section{References}

Aarssen, L. W. and Jordan, C. Y. 2001. Between-species patterns of covariation in plant size, seed size and fecundity in monocarpic herbs. - Ecoscience 8: 471-477.

Bazzaz, F. A. et al. 2000. Reproductive allocation in plants. - In: Fenner, M. (ed.), Seeds: the ecology of regeneration in plant communities. CABI Publ., pp. 1-29.

Coley, P. D. and Aide, T. M. 1991. Comparison of herbivory and plant defenses in temperate and tropical broad-leaved forests. - In: Price, P. W. et al. (eds), Plant-animal interactions: 
evolutionary ecology in tropical and temperate regions. Wiley, pp. 25-49.

Coley, P. D. and Barone, J. A. 1996. Herbivory and plant defenses in tropical forests. - Annu. Rev. Ecol. Syst. 27: 305-335.

Enquist, B. J. and Niklas, K. J. 2002. Global allocation rules for patterns of biomass partitioning in seed plants. - Science 295: 1517-1520.

Foster, S. A. and Janson, C. H. 1985. The relationship between seed size and establishment conditions in tropical woody plants. - Ecology 66: 773-780.

Harper, J. L. and Ogden, J. 1970. The reproductive strategy of higher plants. 1 . The concept of strategy with special reference to Senecio vulgaris L. - J. Ecol. 58: 681-698.

Henery, M. L. and Westoby, M. 2001. Seed mass and seed nutrient content as predictors of seed output variation between species. - Oikos 92: 479-490.

Howarth, S. E. and Williams, J. T. 1972. Crysanthemum segetum. - J. Ecol. 60: 473-584.

Kaplan, J. O. et al. 2003. Climate change and Arctic ecosystems II: modeling, paleodata-model comparisons, and future projections. - J. Geophys. Res. 108: 1-17.

Kollmann, J. and Goetze, D. 1998. Notes on seed traps in terrestrial plant communities. - Flora 193: 31-40.

Leishman, M. R. et al. 2000. The evolutionary ecology of seed size. - In: Fenner, M. (ed.), Seeds: the ecology of regeneration in plant communities. CABI Publ., pp. 31-57.

Levin, D. A. 1974. The oil content of seeds: an ecological perspective. - Am. Nat. 108: 193-206.

Lord, J. et al. 1997. Larger seeds in tropical floras: consistent patterns independent of growth form and dispersal mode. $-\mathrm{J}$. Biogeogr. 24: 205-211.

Download the Supplementary material as file E5613 from $<$ www.oikos.ekol.lu.se/appendix $>$.
Moles, A. T. and Westoby, M. 2003. Latitude, seed predation and seed mass. - J. Biogeogr. 30: 105-128.

Moles, A. T. et al. 2003. Do small-seeded species have higher survival through seed predation than large-seeded species? - Ecology 84: 3148-3161.

Moles, A. T. et al. 2004. Does a latitudinal gradient in seedling survival favour larger seeds in the tropics? - Ecol. Lett. 7: 911914.

Moles, A. T. et al. 2007. Global patterns in seed size. - Global Ecol. Biogeogr. 16: 109-116.

Murray, B. R. et al. 2004. Geographical gradients in seed mass in relation to climate. - J. Biogeogr. 31: 379-388.

Niklas, K. J. and Enquist, B. J. 2002. On the vegetative biomass partitioning of seed plant leaves, stems, and roots. - Am. Nat. 159: 482- 497.

Niklas, K. J. and Enquist, B. J. 2003. An allometric model for seed plant reproduction. - Evol. Ecol. Res. 5: 79-88.

Olson, R. J. et al. 2001. NPP multi-biome: global primary production data initiative products. Data set. - Oak Ridge National Laboratory Distributed Active Archive Center, Oak Ridge, TN, USA, <http://www.daac.ornl.gov>.

Salisbury, E. 1974. Seed size and mass in relation to environment. - Proc. R. Soc. B 186: 83-88.

Swihart, R. K. and Bryant, J. P. 2001. Importance of biogeography and ontogeny of woody plants in winter herbivory by mammals. - J. Mammal. 82: 1-21.

Wilson, A. M. and Thompson, K. 1989. A comparative study of reproductive allocation in 40 British grasses. - Funct. Ecol. 3: 297-302. 